\title{
The two dimensions of Italian academics' public engagement
}

\author{
Monia Anzivino ${ }^{1}$ - Flavio A. Ceravolo ${ }^{1}$ - Michele Rostan ${ }^{1}$
}

Accepted: 10 September 2020 / Published online: 20 October 2020

(c) The Author(s) 2020, corrected publication 2020

\begin{abstract}
The article aims at investigating Italian academics' Public Engagement highlighting its two dimensions, namely "Local Community Engagement" (LCE) and "General Political Engagement" (GPE). It is based on the results of a national survey on academics' third mission activities carried out in the year 2015/2016 collecting information from a representative sample of 5,123 respondents working at 62 universities, with a response rate of $34.2 \%$. In addition to detecting distinct dimensions of academics' Public Engagement, data analysis shows that Italian academics are much more involved in LCE activities than in GPE ones. Although both LCE and GPE are influenced by many common factors, such as academic rank, discipline and being involved in other third mission activities, they also display peculiar traits: LCE activities are more likely to involve academic women while GPE are more likely to be carried out by older academics; LCE activities appear to be contextdependent while GPE activities are not. Hence, the article offers a contribution to a better understanding of the different goals of Public Engagement activities and of their spatial dimension.
\end{abstract}

Keyword Public engagement - Italian academics · Community Engagement · Academics' · political engagement

\section{Introduction}

Over recent decades, universities have been encouraged to enhance the social and economic relevance of their research and to become more accountable for their social and economic impact. This impact has been increasingly measured in terms of their third mission performance (Bauer and Jensen 2011; Bercovitz and Feldmann, 2006; Douglass 2016; Zomer and Benneworth 2011). The societal aspect of third mission performance has been identified with involvement in policy-making, social and

Electronic supplementary material The online version of this article (https://doi.org/10.1007/s1073 4-020-00624-0) contains supplementary material, which is available to authorized users.

Monia Anzivino

monia.anzivino@unipv.it

1 Centre for Study and Research on Higher Education Systems, University of Pavia, Corso Strada Nuova 65, 27100 Pavia, Italy 
cultural life, and the public understanding of science (Schoen and Theves 2006) and in terms of social engagement (Boffo and Moscati 2012). The term "public engagement" (PE) indicates a variety of activities aimed at engaging universities in the public sphere and, correspondingly, at involving the public in the teaching, research and service activities of universities. Especially in the United Kingdom, universities have undertaken many PE initiatives. Starting in 2008, the agencies responsible for the funding of higher education and research, together with other qualified bodies, established pilot projects of collaboration between higher education institutions and civil society organisations, set up the National Co-ordinating Centre for Public Engagement (NCCPE), and promoted the Concordat for Engaging the Public with Research (Research Councils UK et al. 2010). In its turn, NCCPE launched the "Manifesto for Public Engagement" (https://www.publicengagement.ac.uk).

The definition of PE proposed by the NCCPE in the UK has also been widely accepted in Italy. According to the NCCPE "Public engagement describes the myriad of ways in which the activity and benefits of higher education and research can be shared with the public. Engagement is by definition a two-way process, involving interaction and listening, with the goal of generating mutual benefit" (https://www. publicengagement.ac.uk/explore-it/what-public-engagement). According to the Italian national agency for the evaluation of the university system (ANVUR), public engagement consists of a very broad set of non-profit activities, having a cultural and/or educational value aimed at the development of society. Furthermore, the results and contents of teaching and research activities can be shared with, or communicated to, the public in various ways (ANVUR 2016a).

In Italy, all universities provide teaching, research and service activities. State universities dominate Italian higher education, and the non-university and private sectors are small. Most universities are generalist, and there are few specialised institutions. Although there are some clear de facto differences in terms of size, geographical location and research performance, universities are formally considered equal. Their study programs are similar, and they offer Bachelor's Master's and PhD diplomas in accordance with the European framework. The Italian academic profession has always been strictly regulated. Academics were and are civil servants, whose rights, duties and salaries are determined by law, and there is little or no room for individual incentives. ${ }^{1}$ Although some third mission activities - mainly performed on an individual and voluntary basis - have been a part of academic work for decades, the salience of these activities and especially of PE has grown in recent times. Indeed, the introduction and spread of the term is linked to the development of evaluation activities by ANVUR, which is also responsible for assessing university third mission performance. Following the ANVUR's third research assessment exercise (VQR 2011-2014), the notion of third mission was expanded to include activities addressing community health

\footnotetext{
1 In the academic year 2015/2016, when our survey was carried out, there were 96 universities: 66 state institutions including 3 polytechnics, and 5 special higher education institutions, and 30 private institutions, 11 of which providing distance learning. Most students (90\%) attended public universities. In the year 2015, there were 50,369 Italian academics divided into three main ranks, full professors, associate professors and assistant professors. $95 \%$ of them were working at state universities (ANVUR 2016b; MIUR: https://ustat.miur.it/dati/didattica/italia/atenei).
} 
protection, continuing education and public engagement in addition to archaeological sites and museums (ANVUR 2016a). ${ }^{2}$

Although there is general consensus on the definition of PE, there is no unitary view on what specific kinds of activities should be included under the term. In the UK, on the one hand, there is a view that participation in policy-making and relations with the mass media should not be included among PE activities (Research Councils UK et al. 2010). Many researchers, on the other hand, believe that giving interviews, writing articles and books for the general public, communicating with the public through the mass media, and working together with politicians and policy-makers are indeed PE activities (Hamlyn et al. 2015). In Italy, the ANVUR - based, among other sources, on the results of public consultation - proposed a very broad notion of PE, embracing 16 different activities including communication activities and participation in policy-making (ANVUR 2015, p. 41).

In addition to the debate on the definition of PE and on what activities it includes, three other relevant issues should be mentioned. Firstly, there are at least two ways to understand the university's relationship with the public. PE is considered to involve a direct relationship with the general public, however it can include partnerships and collaborations with a number of external organisations that help universities to reach or to involve the public. Both institutions and faculties interact with different domains of the public sphere, populated by organisations such as secondary schools, museums and libraries, publishers and health services, charities, associations and religious communities, local and national governing bodies, and firms (Duncan et al. 2017).

Secondly, the extent of the geographic, or spatial reach of PE is in discussion. It has been argued that PE has a mainly local domain of influence that coincides with the idea of community engagement (Facer et al. 2012; Mason O'Connor et al. 2011). However, PE can also be seen as having a more extensive range of action, on a regional if not a global scale (Arbo et al. 2006; Benneworth et al. 2007; Chatterton et al. 2000; Garlick et al. 2008).

Finally, there is disagreement between those conceiving of PE as a set of individual activities, and those arguing that PE is mainly a collective activity that is carried out in groups, at the departmental, or the institutional level, and that it influences the mission and identity of universities, which may already be or may become "engaged universities" (Watson et al. 2011), "anchor institutions" (Birch et al. 2013), "civic universities" (Goddard and Vallance 2014) or "flagship universities" (Douglass 2016). This contrast is reflected in the ways data on PE activities are collected. For instance, both in the UK and in Italy, public authorities collect data on university PE at both institutional and departmental levels. In the 2014 Research Excellence Framework assessment in the UK, university departments provided more than 6,000 case studies to illustrate the impact of their research on society (https://impact.ref.ac.uk/CaseStudies), including through PE activities (Duncan et al. 2017). Likewise, in Italy, ANVUR collected information on PE activities at both

\footnotetext{
${ }^{2}$ For the first time ever, within the frame of the newly established system for the evaluation and self-evaluation of universities, departments and study programs, all universities and departments were asked to provide information about their PE initiatives, permitting the agency to produce a PE ranking of Italian universities. This ranking, though, was not used to determine a performance-based share of public funding to the university, or to provide individual incentives to faculties. Thus, the assessment of PE activities can be mainly considered on the one hand as a means to urge universities and departments to raise their awareness of $\mathrm{PE}$, to institutionalise it and to consider it as part of their institutional responsibility, and on the other as a source of indirect pressure on faculties to promote new PE initiatives.
} 
institutional and departmental levels (Blasi et al. 2018) in their second (VQR 2004-2010) and third (VQR 2011-2014) research assessment exercises.

Data have also been collected at the individual level, however, mainly through surveys within different types of studies: within international studies on changes in the academic profession (Bentley and Kyvik 2011; Teichler et al. 2013); and within national studies on the activities carried out by specific categories of researchers (Davies 2013; Royal Society 2006); on knowledge exchange between academics and the business, public and third sectors (Abreu et al. 2011); on researchers' public engagement activities (Hamlyn et al. 2015; Jensen 2011; Kreimer et al. 2011; Scamuzzi et al. 2015); and on university external engagement activities (Thune et al. 2016).

Surveys have investigated the association between involvement in PE activities, and academics' demographic characteristics and other factors, such as professional and attitudinal elements. Most of the studies showed higher levels of PE in the humanities, arts and the social sciences than in the other disciplines (STEM) (Burchell et al. 2017; Jensen 2011; Kreimer et al 2011; Kyvik 2005; Rainie et al. 2015; Thune et al 2016) and higher levels of PE for senior researchers and for academics who publish more (Bentley and Kyvik 2011; Kyvik 2005; Jensen et al 2008; Jensen 2011; Thune et al 2016). The effect of gender on PE is more controversial: some studies show that women are more involved in PE than men (Jensen 2011; Jensen et al. 2008) whereas other studies show that men are more likely to engage in PE activities (Bentley and Kyvik 2011; Kreimer et al. 2011). Dudo (2012) does not find a significant difference in levels of engagement for male and female biomedical scientists.

Our study aimed to address three issues that arise from our review of the literature and of the findings obtained by other surveys. The three issues refer to the classification of PE activities, the relationship with the public, and the differences in academics' participation in PE activities. We did this by analysing individual data collected through a national survey on Italian academics' third mission activities. ${ }^{3}$

The first issue concerns the classification of PE activities. As mentioned, there are different ways of conceiving PE. Specialized literature points out two main criteria for the identification and the classification of PE activities. One is based on the content of each activity. The inclusion of some specific activities within the semantic area of the concept of PE is, however, debated. In the UK - for instance - while a research funding agency excludes the participation in policy-making and the relationships with the media from the extension of the concept, academics include these activities in their understanding of PE. The second criterion for identifying different types of PE activities concerns their geographic scale. According to the debate on this point, the geographic scale of PE activities could be considered as varying from local to global.Thus, $\mathrm{PE}$ activities can be classified according to these two dimensions based on their content and their geographic scale. The first aim of the article was to test whether these two theoretical dimensions of PE could be empirically detected in our data. Moreover, the intersection of these two dimensions defines a semantic space of the concept of PE. Thus, we also wanted to explore how the PE activities investigated through the survey are distributed within this semantic space. ${ }^{4}$ Although

\footnotetext{
3 The authors participated in the development and distribution of the survey; Rostan coordinated the field work at the national level, while Anzivino and Ceravolo were part of the research team responsible for the methodological aspects of the survey.

4 As will be shown in the following pages we have been able to detect in our data the two dimensions related to the contents of the activities and their geographic scale. Moreover, we also found that activities having similar contents tend to be spatially organised in a rather similar way.
} 
this exercise does not produce a parsimonious classification of PE activities, nevertheless it provides a heuristic model that may be helpful in constructing a typology of PE activities.

The second issue refers to the relationship with the public. As noted, universities may rely on partnerships and collaborations with external organisations in order to reach or to involve the public. These more or less dense and extended networks of inter-organisational relations may provide universities with a key resource to act as "engaged universities" or as "anchor institutions". Their academic staff may play an important role in establishing and maintaining the relationships with such external organisations. We aimed to investigate the extent to which Italian academics participate in these kinds of relations.

The third issue concerns the differences in academics' degrees of involvement in PE activities. Results from previous surveys show that both biographical and professional traits influence the extent to which academics are involved in PE activities. Furthermore, especially in a country like Italy, characterised by strong regional disparities and an extended and historically rooted network of cities of different sizes, context characteristics may also play a role. We aimed to investigate whether and if so what individual and context characteristics influence Italian academics' involvement in PE activities.

By exploring these issues, the article aims to contribute to a better understanding of various aspects of Italian academics' PE activities and to discuss some implications that our findings may have on the development of university PE strategies. It also intends to provide basic evidence that can be used in future researches in two ways. Firstly, it contributes findings that can be compared to similar evidence gathered in other countries. Secondly, the individual data provided by our survey can be compared to the administrative data collected by ANVUR at the institutional level. More precisely, it will be possible to compare differences, by discipline, university size and geographic location, documented by our survey with similar differences that emerge from data collected by ANVUR in approximately the same period (Blasi et al., 2018).

Before presenting the survey and its main results, followed by a discussion of the three issues, a limitation of our study should be taken into consideration. Our data refer to academics' individual behaviour and attitudes, which cannot be automatically attributed to their institutions. Of course, a university's public engagement is mediated by the behaviour of its staff and it is likely that academics' individual efforts do make a difference. Nevertheless, academics may be involved in PE activities on an individual basis without implying the involvement of their institution. In addition, institutional and departmental strategies for involvement in PE activities may not be captured by individual data. Thus, our study is limited to the investigation of academics' PE activities supposing - but not proving - that at least some of them help universities to engage with society and to participate in political life. $^{5}$

\section{Data and methods}

Data were collected by means of a national survey on academics' third mission activities carried out in 2015/16 as part of a larger project entitled "Universities, innovation and regional economies" (Perulli et al. 2018; Regini et al. 2019). About 15,000 academics,

\footnotetext{
5 Another important limitation concerns the employment status of the academics included in the survey. We interviewed only fully employed faculty members and not researchers or teachers lacking a stable institutional position. However, university third mission activities in Italy do involve these untenured positions, especially due to their role in bridging the academic field with the external environment.
} 
randomly selected from the population list of Italian faculties, were invited to participate in the survey. Completed questionnaires were returned by 5,123 respondents working at 62 universities, a response rate of $34.2 \%$. Four types of third mission activities were taken into consideration: academic entrepreneurship, academic engagement, training and human resource development, and public engagement. Seven aspects of academics' PE, representing various possible ways of linking universities and society were investigated.

As in other studies, we used our data to investigate the extent to which academics participate in PE activities, and differences in involvement as a function of both individual and contextual characteristics. The sample was selected according to two stratification criteria: field of teaching, and the university's geographic location within a macro-region. Field of teaching included 7 categories: humanities and arts; engineering and architecture; social and behavioural sciences; business, economics and law; mathematics, physical and life sciences; agriculture and veterinary; and health. Geographical location included 5 categories, corresponding to Italy's macro-regions: North-West, North-East, Centre, South, and Islands.

The survey differs from previous ones carried out in Italy in that the sample included respondents from almost all the public universities in the country and from all disciplinary fields, and it accurately represents the reference population with very little bias in terms of field of teaching and macro-region.

In order to address the three main issues of the article we relied on several statistical techniques. We used univariate analysis to investigate the degree of diffusion of PE activities, and factor analysis to verify the existence of latent dimensions in the concept of PE emerging from respondents' activities. Finally, to identify what factors are significantly associated with academics' degree of involvement in PE, we relied on multinomial regression. This technique allows all the available information to be used and estimates the effect of each variable net of the others.

\section{Public engagement activities: diffusion and dimensions}

In order to investigate Italian academics' PE activities, we asked respondents seven questions largely inspired by previous research (Abreu et al. 2011; Teichler et al. 2013; Thune et al. 2016). The first referred to people-based activities. Respondents were asked how often in the last five years they had participated in events in collaboration with non-university organisations, such as conferences, exhibitions, fairs, meetings and career days. The second question concerned the sharing of knowledge and competences. We asked respondents how often they had contributed in the previous five years to the design and assessment of public policies. The next three questions referred to activities addressing the territory where their university is located. Respondents were asked how often in the last five years - as university teachers - they a) had collaborated in the carrying out of sport, leisure or cultural events such as exhibitions, concerts, science festivals and such like; b) had been involved in projects with primary and secondary schools; and c) had participated in meetings, conferences or lecturing. Finally, two questions were related to communication activities. We asked respondents how often, in the last five years, they a) had engaged in scientific dissemination activities through the mass media (press, radio, TV, Internet, digital publishing, social media, blogs etc.); and b) had contributed to public debates through the mass media (press, radio, TV, Internet, digital publishing, social media, blogs etc.). 
Table 1 Italian academics' public engagement activities in the five years up to the survey $(\%, \mathrm{~N}=4,978)$

\begin{tabular}{|c|c|c|c|c|c|}
\hline & Never & Rarely & Quite often & Very often & Total \\
\hline Meetings, conferences or lecturing & 14.6 & 27.6 & 36.5 & 21.3 & 100 \\
\hline Events in collaboration with non-university organisations & 27.1 & 27.8 & 32.3 & 12.9 & 100 \\
\hline $\begin{array}{l}\text { Organising sport, leisure or cultural events where the } \\
\text { university is located }\end{array}$ & 43.5 & 26.5 & 21.5 & 8.4 & 100 \\
\hline Projects with primary and secondary schools & 41.8 & 30.5 & 20.6 & 7.2 & 100 \\
\hline Scientific dissemination through the mass media & 44.8 & 39.2 & 13.4 & 2.6 & 100 \\
\hline Contribution to public debates through the mass media & 56.0 & 31.5 & 10.2 & 2.3 & 100 \\
\hline Design and assessment of public policies & 72.3 & 15.6 & 9.4 & 2.6 & 100 \\
\hline
\end{tabular}

Table 2 Factor component analysis of Italian academics' PE activities (factor loadings)

\begin{tabular}{lll}
\hline & Component 1 & Component 2 \\
\hline Events in collaboration with non-university organisations & 0.531 & 0.470 \\
Design and assessment of public policies & 0.733 & 0.002 \\
Scientific dissemination through the mass media & 0.761 & 0.327 \\
Contribution to public debates through the mass media & 0.819 & 0.261 \\
Meetings, conferences or lecturing & 0.376 & 0.713 \\
Organising sport, leisure or cultural events where the university & 0.337 & 0.733 \\
$\quad$ is located & & 0.826 \\
Projects with primary or secondary schools & -0.036 & \\
\hline
\end{tabular}

As Table 1 shows, most of the Italian academics surveyed had been quite heavily involved in meetings, conferences or lecturing, addressing the territory where their institution is located, likely for the benefit of the local community. Almost half had collaborated with non-university external organisations, while $30 \%$ had been engaged in two other activities mainly addressing the local community or the territory surrounding their university. Finally, a minority of academics are involved in communication activities - scientific, or political and cultural.

As already stated (Anzivino et al. 2018), in order to explore whether these activities relate to each other, a factor analysis was conducted on the seven items using the principal components extraction method. ${ }^{6}$ The model showed that one of the seven items - participation in events in collaboration with non-university organizations - correlated with both components (Table 2).

The factor loadings of the other items were more clearly linked to one of the two components. We interpreted the results of the factor component analysis in the following way. Within PE activities, academics share, exchange, or co-generate knowledge with several public bodies or, more simply, transfer or disseminate knowledge to them. In other words - from their point of view - they apply their knowledge in various collaborative settings.

\footnotetext{
6 We used the Varimax rotation of components. The model reproduces $63.6 \%$ of the variance. The first component explains $49 \%$ of the variance and its eigenvalue is 3.428 , while the second component accounts for $14.6 \%$ and its eigenvalue is 1.021 .
} 


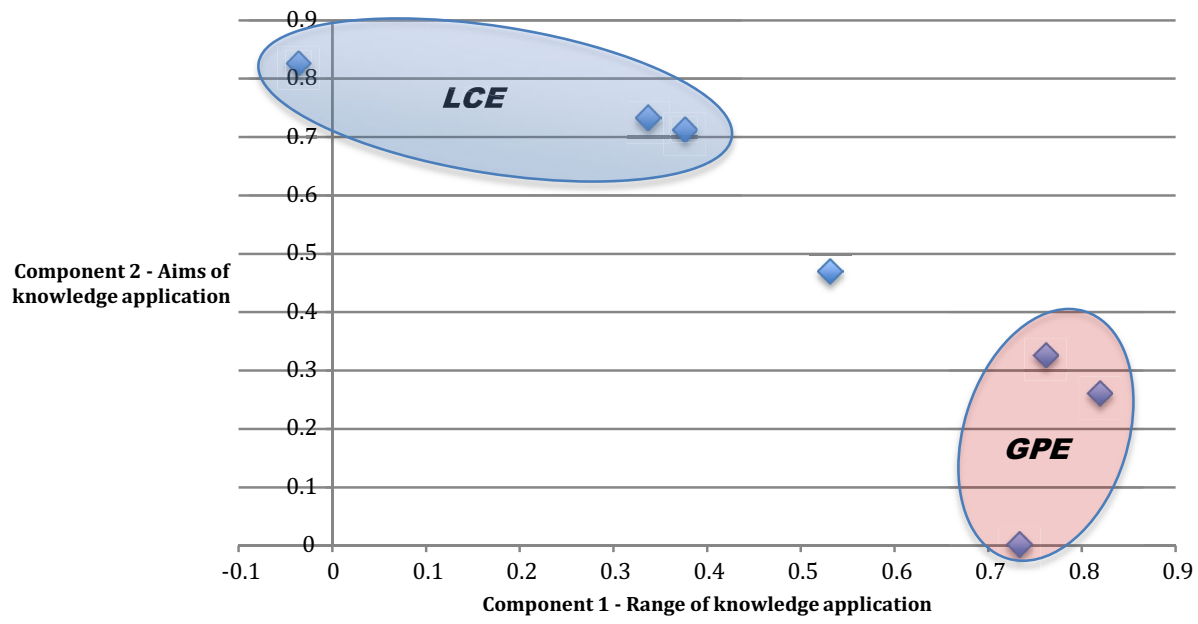

Fig. 1 Scatterplot of the two components or dimensions underlying PE activities identifying two clusters of PE activities

Component 1 seems to refer to the geographic range of application of academics' knowledge, from local to global; while Component 2 seems to represent the aims of knowledge application distinguishing two possible tasks, problem solving, as well as enrichment of the individual.

The seven activities were plotted in a graph with Component 1 as the horizontal $\mathrm{x}$-axis and Component 2 as the vertical y-axis (Fig. 1). Two well-defined clusters emerged. In the upper left corner lie three activities with a rather narrow geographic range of knowledge application, and which are mainly aimed at enrichment of the individual. When academics contribute to the organisation of a city science festival or to the local university college football league, and when they get involved in practical lessons with primary school pupils or give public lectures, their effort is aimed at the enrichment or education of various groups of people belonging or connected to the local community. We call this cluster of PE activities "Local Community Engagement" (LCE).

In the opposite corner - on the lower right - lie the two communication activities and participation in policy-making. In these activities the range of knowledge application is rather extended and knowledge is applied with the direct or indirect aim of solving problems. This could be the case when academics are called upon to give a contribution to the reform of the labour market or of the health system or in the redesigning of electoral districts. Even when the setting of application is rather limited - for instance creating a system for tracing bus mobility within a city - academics' contribution is not place-specific but can be re-applied in other settings and therefore has a general value. Similarly, when academics are interviewed or write an article for a newspaper on climate or ethical issues their contribution may have a general application, depending on the medium. Thus, we call this second cluster "General Political Engagement" (GPE).

Finally, as mentioned before, participating in events in collaboration with non-university organisations may refer either to LCE or to GPE activities. This may explain why this item correlates to both Component 1 and 2 .

Regarding the first aim of the article - whether the two theoretical dimensions of PE could be empirically detected in our data - we can therefore say that within Italian 
Table 3 Italian academics' involvement in LCE and GPE activities (\%) ${ }^{\mathrm{a}}$

\begin{tabular}{llllll}
\hline & Weak GPE & Moderate GPE & Strong GPE & Total & $\mathrm{N}$ \\
\hline Weak LCE & 32.8 & 2.1 & 1.1 & 36.0 & 1,781 \\
Moderate LCE & 17.7 & 2.7 & 1.6 & 22.0 & 1,087 \\
Strong LCE & 24.4 & 7.2 & 10.5 & 42.0 & 2,078 \\
Total & 74.9 & 12.0 & 13.1 & 100.0 & 4,946 \\
$\mathrm{~N}$ & 3,704 & 592 & 650 & 4,946 & \\
\hline
\end{tabular}

a. Pearson chi2 $(4)=634.7 \operatorname{Pr}=0.00$.

academics' PE activities we did indeed detect two different dimensions: the range of application of their knowledge, which refers to the geographic scale of their activities, and the aims of its application, which refers to the content of their activities. These dimensions define a semantic space for the concept of PE and identify two different clusters of PE activities, namely LCE and GPE activities. While Italian academics' participation in LCE activities is considerable, their participation in GPE activities is rather limited. The emergence of these two different clusters of PE activities suggests that the analysis of the factors enhancing or hindering academics' involvement in them should be carried out separately.

\section{Characteristics influencing public engagement activities}

In order to investigate what factors influence Italian academics' PE, we started from the two sets of activities found in the previous stage of analysis - namely Local Community Engagement (LCE) activities and General Political Engagement (GPE) activities - and we conducted two multivariate analysis models.

The dependent variable (see Table A1 in the Appendix) for both models - degree of involvement - was obtained from the combination of the items corresponding to each set of activities, as determined in the preceding factor analysis. In order to quantify degree of involvement, we firstly coded each item into dichotomies, with value 0 attributed to the answers "Never" and "Rarely" and value 1 attributed to the answers "Quite often" and "Very often". Then we summed the values for items in the GPE activities and items in the LCE activities, and we expressed the result as a percentage. We then created three categories (weak, moderate and strong involvement) as follows: a) a score of zero points on all the respective items in either LCE or GPE activities was classed as weak involvement; b) a score from 1 to 49.99 per cent was classed as moderate involvement; c) a score of 50 per cent or more, or of less than $50 \%$ for an academic who nevertheless participated very frequently in at least one activity, was classed as strong involvement, since in our view even participating intensively in only one activity can be very demanding and engaging.

It is worth noting that strong involvement is more frequent in LCE than in GPE activities (Table 3). In addition, $22 \%$ of the respondents are involved, moderately or strongly, in both LCE and GPE activities, while $42 \%$ of them concentrate their efforts mainly on LCE (i.e. moderate+ strong involvement in LCE and weak in GPE) and just 3\% concentrate theirs only on GPE (i.e. moderate + strong involvement in GPE and weak in LCE).

The independent variables (see Table A2 in the Appendix) of the models can be aggregated into three groups of characteristics: 
- Socio-demographic characteristics: age, gender, social and cultural origins;

- Professional and academic characteristics: academic rank, discipline, seniority, individual scientific productivity in the five years before the interview, external professional experience before and after university recruitment, number of research assistants (research fellows, PhD students, medical interns), involvement in other third mission activities, research orientation;

- Context characteristics: university size in terms of number of students, university location within a macro-region, and size of the city where the university is located.

\section{Local Community Engagement}

We started our analysis by looking at the multivariate model for LCE activities with intensity of involvement as dependent variable, focusing on the differences between strong and weak involvement (Table 4, LCE model).

Except for gender, socio-demographic characteristics were not found to be important in discriminating the probability of being involved either weakly or strongly in LCE activities. Female academics were found, ceteris paribus, to be more likely to be strongly involved than males.

Among professional and academic characteristics, some were more highly associated with LCE than others. Having had at least one professional experience with non-academic organizations, before or after university recruitment, increased the probability of being strongly, rather than weakly, engaged in LCE. Academic rank was important and full professors were more likely to be strongly involved in LCE activities than associate or assistant professors. Academics in the area of humanities and arts and those in the social and behavioural sciences, were more likely to be strongly engaged. On the contrary, academics belonging to the health sector were the least likely to be involved, net of all other factors. Scientific productivity was found to be associated with LCE. The greater the number of publications - articles published in academic volumes or scientific journals - in the five years prior to the interview, the more intense was involvement in LCE activities. Being involved in other third mission activities was also positively associated with LCE. Likewise, having a numerous group of research colleagues (fellows, interns and $\mathrm{PhD}$ students) was associated with a higher probability of being strongly, rather than weakly, involved. While socially oriented research was positively associated with strong participation in LCE activity, there was no significant relationship between commercially oriented, applied or theoretically oriented research and LCE.

Finally, we looked at some context factors, the characteristics of the university where respondents work. Working in a small university rather than in a large or very large one, increased the probability of being strongly involved in LCE, as did working in a university located in a small town rather than in a big city. The location of the university was also important in terms of its geographical location. Academics working in universities located in Central Italy or in the North-East were found to be less active in LCE than their colleagues who work in other geographic macro-regions, net of the other factors considered in the model.

\section{General Political Engagement}

The multivariate model for GPE (Table 4, GPE model) showed that socio-demographic characteristics, except for the age of respondents, were irrelevant. Age was positively 


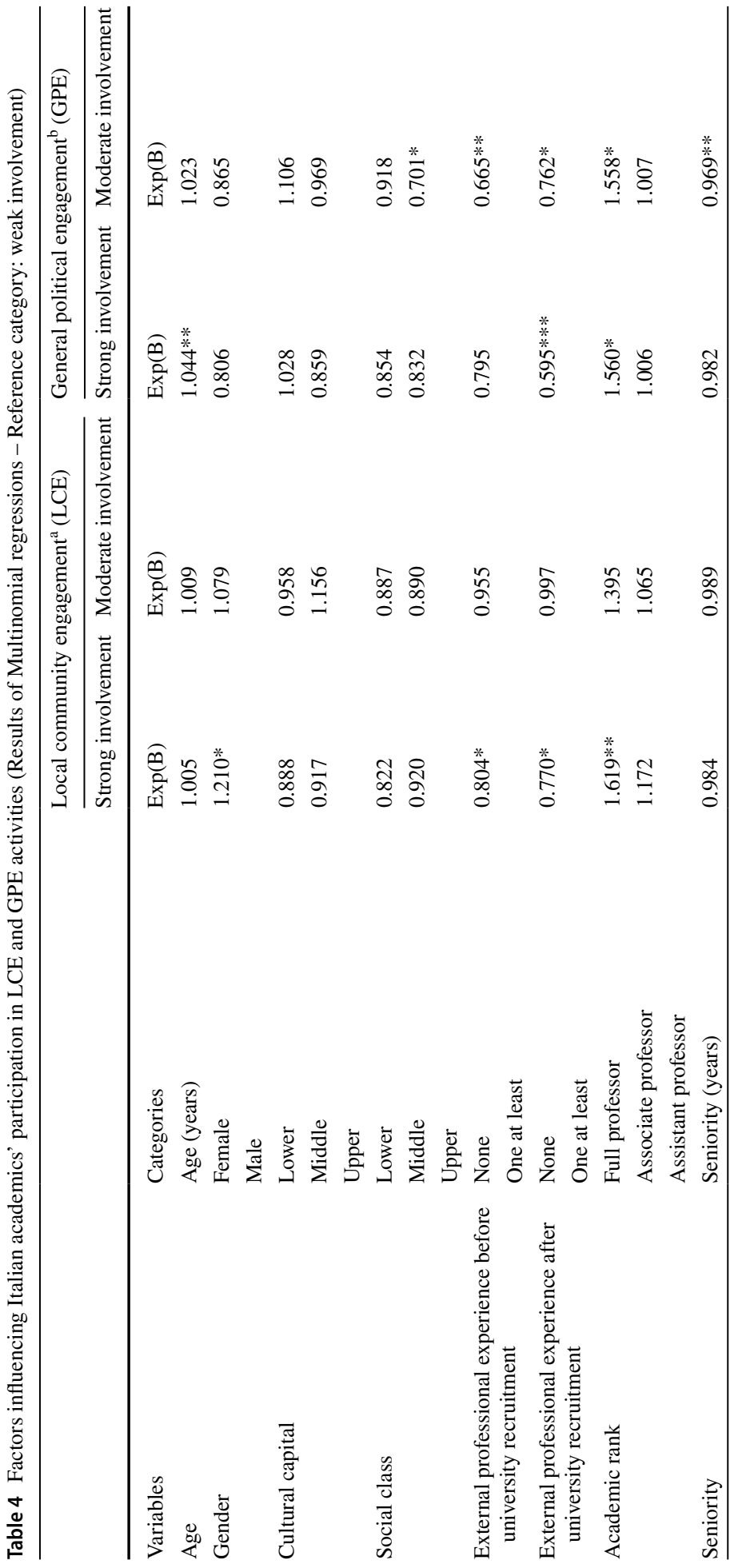




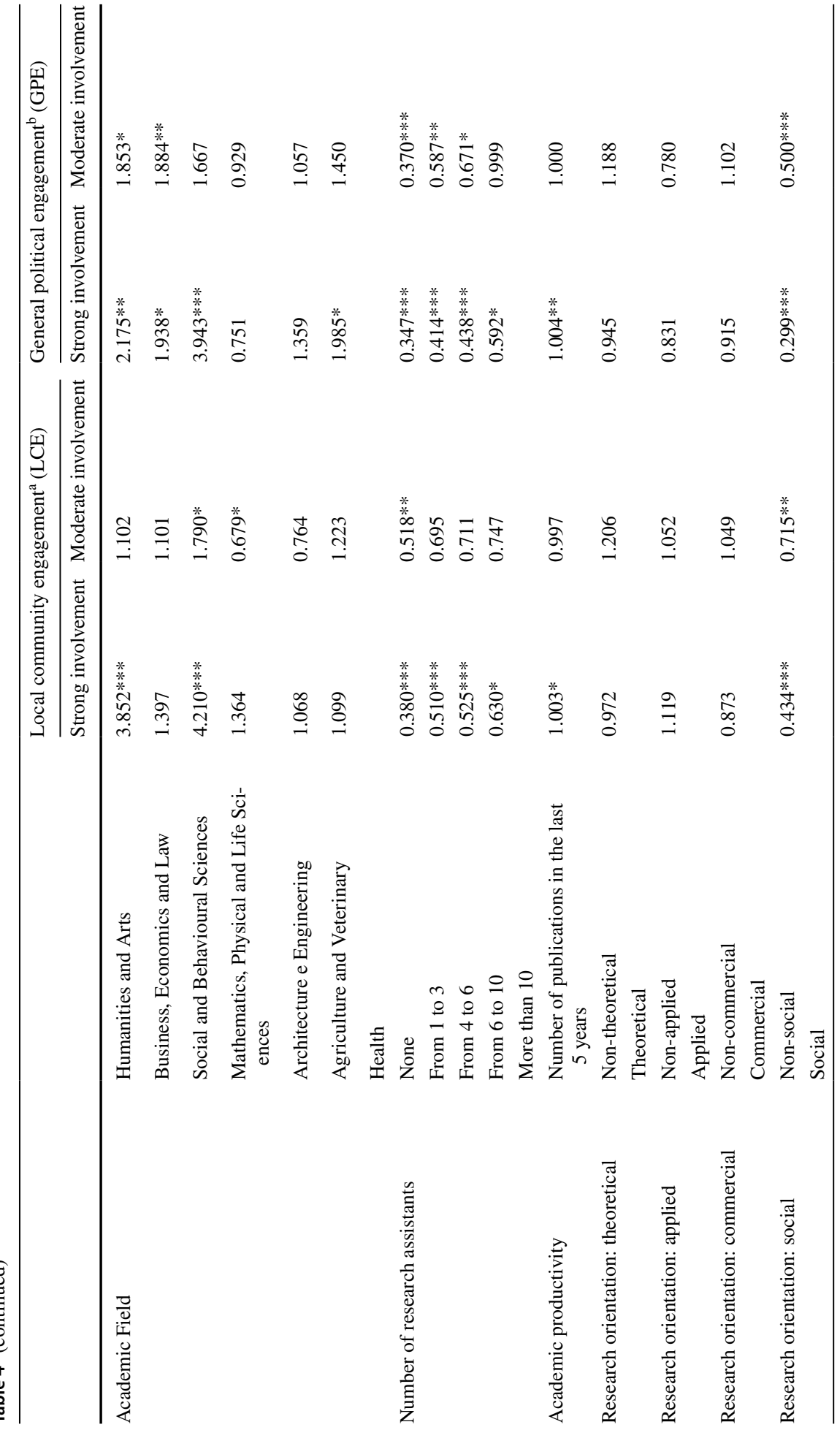




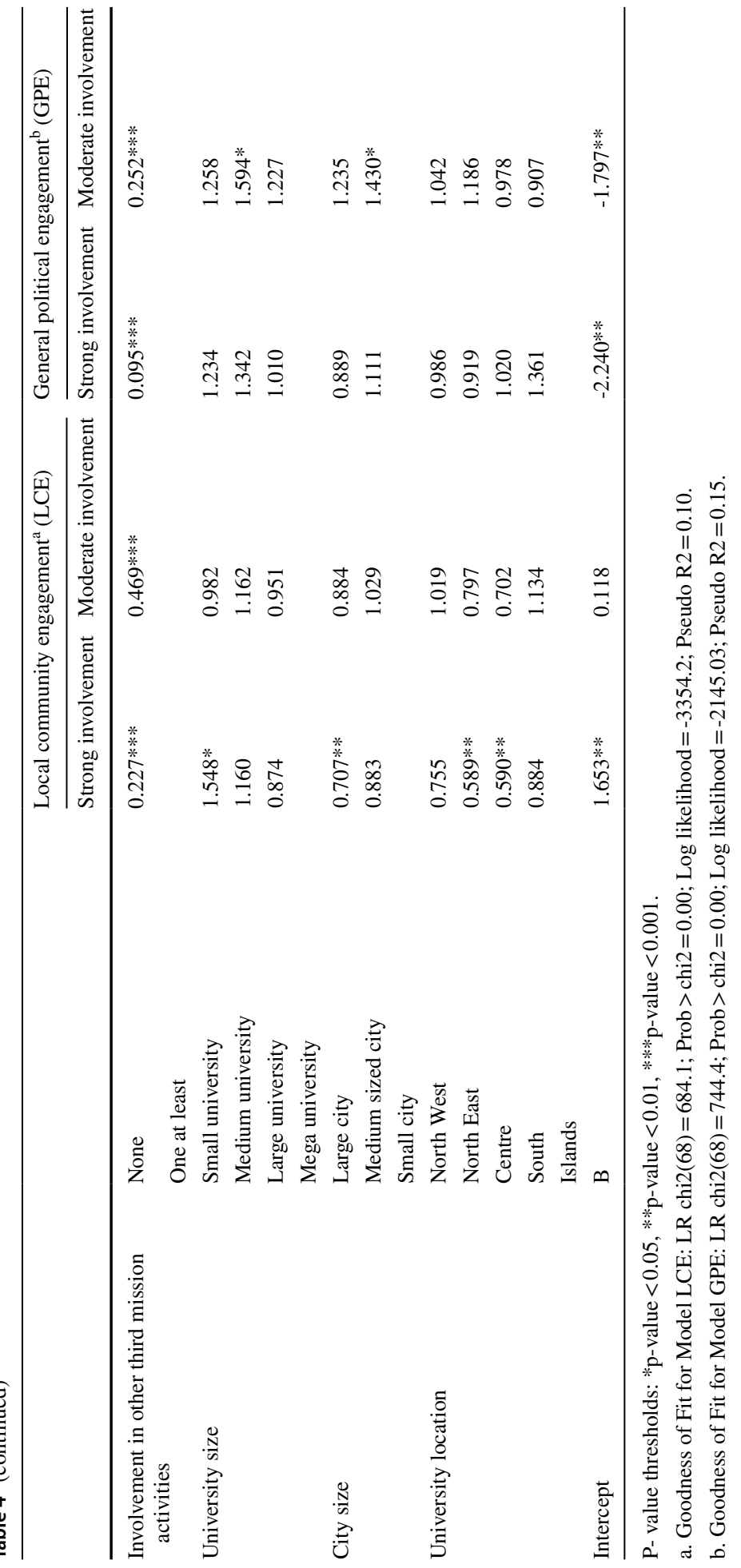


associated with GPE: older academics were more likely to be strongly engaged than younger ones.

A professional experience with external organizations was associated with higher participation in GPE activitiesonly, however, if it was carried out after entering university as an academic. Academic rank was also positively associated with GPE, with full professors being more likely to be strongly involved in these activities. Academics belonging to the social and behavioural sciences were most probable to be strongly involved in GPE activities, followed by their colleagues in the humanities and arts. Academics from business, economics and law, and from agriculture and veterinary, were less likely to be strongly engaged in GPE activities than those from the social and behavioural humanities and the arts and the sciences, but more likely to be strongly engaged in these activities than their colleagues in the health sciences. Number of research assistants was also positively associated with stronger involvement in GPE, as was scientific productivity. Carrying out socially-oriented research enhanced the probability of being strongly engaged, as did involvement in other types of third mission activities.

It is worth noting that, unlike for LCE activities, participation in GPE activities was not significantly related to context characteristics. Academics have the same probability of being strongly involved in GPE activities whether they work in small or large universities, in big cities or small towns, in the North or in the South of Italy.

\section{Conclusions and implications}

Relying on an analysis of individual data collected through a national survey, the study reported in this article aimed to improve our understanding of involvement in PE by providing an empirically based contribution to classify academics' activities, to shed some light on the role academics play in fostering universities' relationships with external organisations, and to explore the differences in their involvement in such activities, as a function of both individual and contextual characteristics. We think the collected findings may have some implications for university PE strategy development in Italy.

The analysis of the seven considered PE activities empirically confirmed the existence of two dimensions for PE, one related to its contents and the other to its geographic scale. The results of the analysis, though, also bring us a step forward in the understanding of PE. Indeed, they suggest that activities having different contents - aimed at the enrichment of the individual or at problem solving - are carried out on different geographic scales, allowing us to identify two distinct sets of activities, which we named Local Community Engagement (LCE) and General Political Engagement (GPE). Although this is only an empirical finding showing that within the semantic space identified by the two dimensions Italian academics' PE activities aggregate in a meaningful way, it nevertheless provides an interpretative model useful to classify these activities. The identification of these two sets of activities supports the view that communication activities and involvement in policy-making should be considered separately from other PE activities. Other findings also emphasize the differences between the two sets of activities. Firstly, Italian academics appear to be much more involved in LCE than in GPE activities. Secondly, while some personal and professional traits were associated with participation in one particular type of activity, they were not associated with participation in the other. Thirdly, while LCE activities appear to be dependent on some characteristics of the context where academics work, GPE activities are not. 
The identification of two distinct sets of PE activities, though, does not mean that they are unrelated. Firstly, 22\% of the respondents are involved, at least moderately, in both LCE and GPE activities. Secondly, both LCE and GPE activities seem to imply a good deal of collaboration with external organisations. Thirdly, being involved in other types of third mission activities - namely academic entrepreneurship, academic engagement, training and human resources development - increased the likelihood of being strongly involved in both LCE and GPE activities. Fourthly, a common set of professional characteristics were associated with academics' participation in both LCE and GPE activities.

Universities should not consider PE as a homogeneous field: a more nuanced and multidimensional understanding is needed. Distinguishing LCE and GPE activities is a possible way to achieve this. Appreciating the differences between the two sets of activities should help universities improve their strategies. For instance, it should enhance universities' ability to select those within their faculty who are better equipped to pursue different PE objectives and to support them accordingly. Differences should not be overemphasized, though. Our evidence shows that numerous similarities connect the two sets of activities, providing useful insights for the development of institutional PE as well.

One example is offered by the crucial role that highly productive full professors in the humanities and the social sciences play in both LCE and GPE activities. Finally, data analysis results strongly indicate that universities should not consider PE as a standalone sector. The fact that participating in other third mission activities such as patenting, starting up new businesses, research collaboration with industry, consultancy or workers' training was strongly associated with academics' involvement in PE activities, suggests that universities' third mission forms a multifaceted, but also strictly connected, web of activities linking them to society. Findings from our research suggest that in Italy - as in other countries - there is a rather large group of pro-active and polyvalent academics who can act as propellers of university engagement.

A considerable proportion of respondents is involved, very or quite often, in events carried out in collaboration with non-university organisations, such as conferences, exhibitions, fairs, meetings, and career days (45\%). These people collaborate with external organisations in order to reach the public through various events. Thus, it can be said that academics' relationship with the public is mediated to a remarkable extent by external organisations, presumably both in LCE and GPE activities.

Moreover, professional experiences outside the university - working for or with nonuniversity research centres or institutes, health institutions, schools, government or public organizations, profit organizations in the private sector, or non-profit organizations in the private sector (foundations, NGOs, etc.) - favours academics' participation in both LCE and GPE activities, except in the case of GPE, for experiences carried out before entering the academic profession. We interpret this finding as a signal, not only of the importance of professional connections with a wide range of external organisations in fostering PE activities, but also of the existence of a well-established network linking universities to external organisations through faculty's professional experience outside the university.

All these links at the individual level may also have an impact at the institutional one. In fact, these already established networks of relations may provide Italian universities with an important organisational resource to develop their PE strategies, enriching their institutional portfolio of collaborations and partnerships.

The results of the data analysis highlighted some substantial differences in Italian academics' involvement in PE activities. The first concerns gender differences. As mentioned, the influence of gender on the participation in PE activities is controversial. While some previous findings document that being female is either positively or negatively associated with 
the level of engagement in these activities, other studies report no association. Our findings may shed light on this matter. In our analysis, being female favoured participation in LCE activities compared to being male, while no gender difference was recorded for involvement in GPE activities. Thus, gender may influence participation in PE activities depending on the type of activity. When PE activities are aimed at personal development or have a broad educational purpose and are addressing the local community, academic women are more likely to be strongly involved in them than academic men. No differences between men and women were found for PE activities aimed at solving societally relevant problems, that have a possible range of application settings from local to global. The difference between LCE and GPE activities remains to be explained. It may be that, in the local society, female academics - like all other women - are expected, more than male academics are, to act as care givers or to engage with people, but it might also be that female academics are more deeply embedded in local networks than male academics, favouring more intense local engagement on their part. Moreover, it may also be that access to GPE activities depends so strongly on personal traits related to age and academic rank, that gender differences are less relevant in influencing academics' participation in such activities. For instance, access to the mass media - a sort of tribune's right to public speech - may rest on personal reputation gained through many years of professional activity irrespective of gender.

The second difference that is worth mentioning involves academic discipline. Our data confirmed that working in the fields of the humanities and arts and in the fields of the social and behavioural sciences, favours more intense involvement in PE activities. The distinction between LCE and GPE activities, though, adds a further element to the picture. In fact, a wider swathe of disciplines is strongly involved in GPE activities than is involved in LCE activities. Seemingly, when the design and assessment of public policies, and public debates and scientific dissemination through the mass media are at stake, not only the humanities and the social sciences faculties but also business, economics and law, and their colleagues from agriculture and veterinary are more likely to be strongly involved than academics from the remaining disciplinary areas.

The third difference concerns the context within which PE activities are carried out. The size of the institution academics are working in, the size of the city and the characteristics of the macro-region where the institution is located was associated with higher participation in LCE activities, while both participation in the policy-making process and access to the mass media appear to be totally unrelated to these variables. It might not come as a surprise that academics' involvement in activities benefitting the local community was found to be more intense in small cities and small universities, while their involvement in activities that mainly address an extra-local audience was less dependent on traits of the institution or the locality. Slightly more surprising is the relationship between the politically charged North-South divide and participation in both LCE and GPE activities. Multivariate analysis found no difference in involvement in LCE and GPE activities between academics working in universities in Southern Italy and the Islands - where the less developed regions of the country are found - and their colleagues working in universities in North-Western regions - the more developed ones. At the same time, working in Central and North-Eastern Italy was associated with slightly less participation in LCE activities, while it had no significant relationship with involvement in GPE activities.

Thus, it seems that the traditional North-South divide has no influence on participation in LCE and GPE activities. This finding, though, may find different explanations. On the one hand, Italian academics seem to play a similar civic role to the benefit of the local community in a variety of socio-economic contexts. On the other hand, they may participate in policy-making and have access to the mass media in a similar way in both Northern 
and Southern Italy because these activities are equally widespread in the two parts of the country. The picture is further complicated by the finding concerning Central and NorthEastern regions. These regions - aggregated into the so-called Third Italy - are traditionally considered to have a strong sense of civic responsibility and an intense social and cultural life within their cities and communities. Thus, the finding that working in universities located in these regions was associated with lower academic participation in LCE activities is unexpected and deserves further investigation.

These differences could influence PE strategies both at the institutional and at the system levels. At the institutional level, research findings suggest that female academics may be an important resource for strengthening universities' local PE strategies. At the system level, our results bring to light at least two issues. First, university PE in Italy could be further developed starting from the role that small universities can play in small cities where our data analysis showed that individual academics are more strongly involved in LCE activities. Second, our research findings show what an important role universities in Southern regions and the Islands could play in the development of their local societies, as academics working in Southern universities are by no means less involved in LCE activities than their colleagues working in North-Western universities. In both instances - the Italy of small cities, and Southern Italy and the Islands - findings on Italian academics' participation in LCE activities suggest that PE may be a way to enhance the role, the contribution to society and the legitimisation of the university system in Italy.

Funding Open access funding provided by Università degli Studi di Pavia within the CRUI-CARE Agreement. Data on Italian academics' Public Engagement have been collected by the survey "Le attività di terza missione degli accademici italiani" within the research project "Universities, innovation and regional economies" co-funded by the Italian Ministry of University and Research and four Universities: Turin, Milan, Pavia and Florence (MIUR_-Programmi di Ricerca Scientifica di Rilevante Interesse Nazionale 2010-2011, Contract n. 2010WN5KCP_004).

Open Access This article is licensed under a Creative Commons Attribution 4.0 International License, which permits use, sharing, adaptation, distribution and reproduction in any medium or format, as long as you give appropriate credit to the original author(s) and the source, provide a link to the Creative Commons licence, and indicate if changes were made. The images or other third party material in this article are included in the article's Creative Commons licence, unless indicated otherwise in a credit line to the material. If material is not included in the article's Creative Commons licence and your intended use is not permitted by statutory regulation or exceeds the permitted use, you will need to obtain permission directly from the copyright holder. To view a copy of this licence, visit http://creativecommons.org/licenses/by/4.0/.

\section{References}

Abreu, M., Grinevich, V., Hughes, A., \& Kitson, M. (2011). Knowledge exchange between academics and the business, public and third sectors. UK Innovation Research Centre: University of Cambridge and Imperial College London.

ANVUR - Agenzia Nazionale di Valutazione del Sistema Universitario e della Ricerca (2015). La valutazione della terza missione nelle università italiane. Manuale per la valutazione. Roma: ANVUR, 1 aprile.

ANVUR - Agenzia Nazionale di Valutazione del Sistema Universitario e della Ricerca / Commissione di Esperti della valutazione della Terza Missione (2016a). Valutazione della Qualità della Ricerca 20112014 (VQR 2011-2014). Criteri per la valutazione delle attività di Terza Missione delle Università e degli Enti di Ricerca. Roma: ANVUR, 15 gennaio. 
ANVUR Agenzia Nazionale di Valutazione del Sistema Universitario e della Ricerca 2016 Rapporto biennale sullo stato del sistema universitario e della ricerca 2016b ANVUR Roma

Anzivino, M., Ceravolo, F. A., \& Rostan, M. (2018). Il Public Engagement degli accademici italiani: un'opportunità di rapporto tra università e territorio. Stato e Mercato, 114(3), 547-581.

Arbo, P., \& Benneworth, P. (2006). Understanding the Regional Contribution of Higher Education Institutions: A Literature Review. Paris: OECD/IMHE.

Bauer, M., \& Jensen, P. (2011). The mobilization of scientists for public engagement. Public Understanding of Science, 20(1), 3-11.

Benneworth, P., Sanderson, A. (2007). Building Institutional Capacity for HEI Regional Engagement in a Sparse Innovation Environment: A Case Study of Knowledge House (NE England), OECD/IMHE International Conference, «Globally Competitive, Locally Engaged Higher Education and Regions», 19-21 September, Valencia, Spain.

Bentley, P., \& Kyvik, S. (2011). Academic staff and public communication: a survey of popular science publishing across 13 countries. Public Understanding of Science, 20(1), 48-63.

Bercovitz, J., \& Feldmann, M. (2006). Entrepreneurial universities and technology transfer: A conceptual framework for understanding knowledge-based economic development. Journal of Technology Transfer, 31(1), 175-188.

Birch, E., Perry, D. C., Taylor, H. L., \& jr. (2013). Universities as anchor institutions. Journal of Higher Education Outreach and Engagement, 17(3), 7-15.

Blasi, B., Romagnosi, S., \& Bonaccorsi, A. (2018). Do SSH Researchers Have a Third Mission (And Should They Have)? In A. Bonaccorsi (Ed.), The Evaluation of Research in Social Sciences and Humanities (pp. 361-392). Cham: Springer.

Boffo, S., \& Moscati, R. (2012). New University Roles in Contemporary Society: Third Mission Development in some European Higher Education Systems, 25 ${ }^{\text {th }}$ CHER Conference "Higher Education and Social Dynamics". Belgrade, 10 -12 September.

Burchell, K., Sheppard, C., \& Chambers, J. (2017). A "work in progress"?: UK researchers and participation in public engagement. Research for All, 1(1), 198-224.

Chatterton, P., \& Goddard, J. (2000). The Response of Higher Education Institutions to Regional Needs. European Journal of Education, 35(4), 475-496.

Davies, S. R. (2013). Research staff and public engagement: a UK study. Higher Education, 66(6), 725-739.

Douglass, J. A. (Ed.) (2016). The New Flagship University. Changing the Paradigm from Global Ranking to National Relevancy. New York: Palgrave Macmillan.

Dudo, A. (2012). Toward a model of scientists' public communication activity: The case of biomedical researchers. Science Communication, 35(4), 476-501.

Duncan, S., Manners, P., \& Miller, K. (2017). Engaging Publics with Research: Reviewing the REF 2014 Impact Case Studies and Templates. Bristol: NCCPE.

Facer, K., Manners, P., \& Agusita, E. (2012). Towards a Knowledge Base for University-Public Engagement: Sharing Knowledge. Building Insight, Taking Action, NCCPE: Bristol.

Garlick, S., \& Langworthy, A. (2008). Benchmarking University Community Engagement: Devising a National Approach in Australia. Higher Education Management and Policy, 20(2), 105-117.

Goddard, J., \& Vallance, P. (2014). The University and the City. London: Routledge.

Hamlyn, B., Shanahan, M., Lewis, H., O’Donoghue, E., Hanson, T., \& Burchell, K. (2015). Factors affecting public engagement by researchers. A study on behalf of a Consortium of UK public research funders. London: TNS-BMRB

Jensen, P., Rouquier, J., Kreimer, P., \& Croissant, Y. (2008). Scientists who engage with society perform better academically. Science and public policy, 35(7), 527-541.

Jensen, P. (2011). A statistical picture of polarization activities and their evolutions in France. Public Understandig of Science, 20(1), 26-36.

Kreimer, P., Levin, L., \& Jensen, P. (2011). Popularization by Argentine researchers: the activities and motivations of CONICET scientists. Public Understanding of Science, 20(1), 37-47.

Kyvik, S. (2005). Popular science publishing and contributions to public discourse among university faculty. Science communication, 26(3), 288-311.

Mason O‘Connor, K., Owen, D., Lynch, K., \& Hill, S. (2011). Literature review. Embedding community engagement in the curriculum: An example of university-public engagement. Bristol: NCCPE.

Perulli, A., Ramella, F., Rostan, M., \& Semenza, R. (Eds.) (2018). La terza missione degli accademici italiani. Bologna: Il Mulino.

Pew Research Center (2015). How Scientists Engage the Public. https://www.pewinternet.org/2015/02/15/ how-scientists-engage-public/

Regini, M. \& Trigilia, C. (Eds.) (2019). Università e innovazione. Il contributo degli atenei italiani allo sviluppo regionale. Bologna: Il Mulino. 
Research Councils UK et al. (2010). Concordat for engaging the public with research: a set of principles drawn up by the funders of research in the UK, https://www.rcuk.ac.uk/per/Pages/Concordat.aspx

Royal Society (2006). Science Communication: Survey of factors affecting science communication by scientists and engineers, https://royalsociety.org/policy/publications/2006/science-communication/

Scamuzzi, S., \& Tipaldo, G. (Eds.) (2015). Apriti scienza. Il presente e il futuro della comunicazione della scienza in Italia tra vincoli e nuove sfide. Bologna: Il Mulino.

Schoen, A., \& Theves, J. (Eds.) (2006). Strategic management of university research activities. Methodological guide. Lugano: PRIME Project Observatory of the European University.

Teichler, U., Arimoto, A., \& Cummings, W. K. (2013). The Changing Academic Profession. Major Findings of a Comparative Survey. Dordrecht: Springer.

Thune, T., Reymert, I., Gulbrandsen, M., \& Aamodt, P. O. (2016). Universities and external engagement activities: Particular profiles for particular universities? Science and Public Policy, 43(6), 774-786.

Watson, D., Hollister, R., Stroud, S. E., \& Babcock, E. (2011). The Engaged University. International Perspectives on Civic Engagement. New York: Routledge.

Zomer, A., \& Benneworth, P. (2011). The rise of the university's Third Mission. In J. Enders, H. F. de Boer, \& D. Westerheijden (Eds.), Reform of higher education in Europe (pp. 81-103). Rotterdam: Sense Publishers.

Publisher's Note Springer Nature remains neutral with regard to jurisdictional claims in published maps and institutional affiliations. 